\title{
COMPARISON OF TWO BALANCE TRAINING PROGRAMS ON BAL- ANCE OF GERIATRIC POPULATION OF MADHYA PRADESH, INDIA
}

\author{
Divya Khare ${ }^{* 1}$, Jyoti Shrivastava ${ }^{2}$.
}

${ }^{* 1}$ Professor, Physiotherapy Department, Ayushman College, Bhopal, Madhya Pradesh, India.

${ }^{2}$ Research Scholar, Physiotherapy Department, Ayushman College, Bhopal, Madhya Pradesh, India.

\section{ABSTRACT}

Aim: To compare effect of two balance training programs on balance of geriatric population of Madhya Pradesh, India.

Methodology: 50 subjects were selected randomly. The subjects were assessed on the 3 balance scales before the exercises and after four weeks of training

Result: Significant Results were found.

Conclusion: Study concludes that the subjects who participated in the specific exercise program significantly improved their functional ability.

KEY WORDS: Balance Training Programs, Geriatric Population, Exercise Program, Functional Ability.

Address for correspondence: Dr. Divya Khare, Professor, Physiotherapy Department, Ayushman College, Bhopal, Madhya Pradesh, India. E-Mail: adivyakhare@gmail.com

Access this Article online

Quick Response code

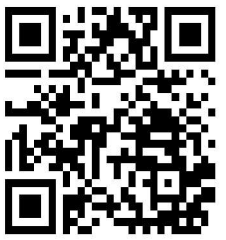

DOI: $10.16965 /$ ijpr.2018.103

Journal Information

International Journal of Physiotherapy and Research

ICV for 2016 ISSN (E) 2321-1822 | ISSN (P) 2321-8975

86.93 https://www.ijmhr.org/ijpr.html

Dol-Prefix: https://dx.doi.org/10.16965/ijpr

(cc) $\mathrm{ET}-\mathrm{Ni}-\mathrm{BH}$

\section{Article Information}

Received: 19 Jan 2018

Peer Review: 21 Jan 2018

Revised: None
Accepted: 19 Feb 2018

Published (O): 20 Mar 2018

Published (P): 11 Apr 2018

\section{INTRODUCTION}

Balance is defined as the ability to keep the body's centre of mass within the limit of the base of support, it is required for many functional activities daily life such as mobility \& fall avoidance [1]. In elderly, falls often precipitates a series of events with catastrophic potential. Complaints of dizziness and disequilibrium increases with increased age. $65 \%$ of individuals older than 60 years of age experience dizziness or loss of balance often on daily basis. Some degree of imbalance is present in all individuals older than 60 years. This is the result of generalized functional degeneration. Initially the imbalance is a situational and manifests when lightening reflexes cannot meet the demands of a challenging environment such as slippery surfaces. As the functional degeneration progresses the imbalance occurs during everyday activities, independent ambulation becomes difficult and likelihood of falls increases. When the inability is constant the individual restore the use of cane a walker or wheelchair [1].

Several investigators have examined the effect of a single form of exercise on balance in older adults, with mixed results balance training has shown to improve the different aspects of postural control. Individualized balance training has shown improvement in balance scores such as BBS and dynamic gait index and a 9 week balance training by Ledin et al., also led to changes in balance performance [2].

Several studies found the effect of short term balance training or effects of different exercise 
program on falls and mobility of older adults. However there is limited information about the performance of the very elderly on balance [2]. It becomes difficult to determine which type of balance training is the most effective from the existing evidence and the view is supported by Howe et al [2].

\section{METHODOLOGY}

Table 1: Summary of exercises for Group A and B.

\begin{tabular}{|l|l|}
\hline \multicolumn{1}{|c|}{ GROUPA } & \multicolumn{1}{|c|}{ GROUP B } \\
\hline 1. Flexibility exercise - & 1. Stepping in all directions \\
Hamstring stretch - & -Forward direction \\
Gluteus maximus and hip flexor & - side way direction \\
stretch & -Backward direction \\
Gastrocnemius and soleus stretch & 2. Sit to stand exercises \\
2. Strengthening exercises - lower limb muscles & 3. Reaching to limits of stability \\
quadriceps (sitting and straight leg raises) & and Sideways reach task \\
Hamstrings & Ball games with cognitive task \\
Gluteus maximus & - catching \\
Gluteus medius & -throwing \\
3. Postural control exercise & - kicking \\
Head and neck & 5.Stair climbing \\
$\quad$ Trunk & \\
4. Bridging & \\
5. Sit to stand to sit & \\
\hline
\end{tabular}

Procedure: Random selection of patient with age group 60 to more than 60,70 subjects for current study were sorted, out of which only 60 subjects could meet the inclusion and exclusion criteria. The procedure of the study was explained to 60 cases and informed consent was obtained from all 60 subjects. All cases were asked whether they were afraid of falling. Out of sixty cases only 50 had completed the full protocol of four weeks. Total 50 older adults were interviewed and scored on MMSE and were recruited in data analysis of study. All fifty cases were questioned regarding by number of falls in the last 12 months. The subjects were assessed on the 3 balance scales before the exercises and after four weeks of training ,Berg balance scale (BBS) - Berg balance scale was orginialy developed for assessing postural control and is widely used in many fields or rehabilitation. BBS consists of 14 activiteswhich are scored on a 5 point ordinal scale with maximum score 56 and minimum score 0. OLST with eyes open - the OLST Scoreof subjects is evaluated by standing on a single limb with eyes open, the test is perform for 30 seconds. Falls efficacy scale - International - Falls efficacy scale international is a self reported questionnaire that measure the level of concern about falling during social and physical activities inside and outside the home whether or not the person actually does the activity.

All the 50 cases were randomly divided into two groupswho underwent following therapy-

\section{RESULTS}

Table 2: Comparison of score of berg balance scale in Group A and Group B between pre- intervention and post intervention sampling stages.

\begin{tabular}{|c|c|c|c|c|}
\hline Sampling Stage \& group & $\begin{array}{c}\text { Score on BBS } \\
\text { Mean } \pm \text { SD }\end{array}$ & Mean Diff & t-statistic & $\begin{array}{l}\text { p-value } \\
\text { (LOS) }\end{array}$ \\
\hline \multicolumn{5}{|c|}{ Group A (General Exercise Program) } \\
\hline Pre- intervention & $32.04 \pm 4.94$ & \multirow{2}{*}{7.76 points } & \multirow{2}{*}{24.43} & \multirow{2}{*}{$p<0.001$} \\
\hline Post-intervention & $39.80 \pm 4.50$ & & & \\
\hline \multicolumn{5}{|c|}{ Group B (Specific exercise program) } \\
\hline Pre- intervention & $31.88 \pm 5.95$ & \multirow{2}{*}{11.36 points } & \multirow{2}{*}{26.32} & \multirow{2}{*}{$p<0.001$} \\
\hline Post-intervention & $43.24 \pm 5.43$ & & & \\
\hline
\end{tabular}

\# The mean differences are highly significant at the 0.001 level of significance. The degrees of freedom are 24. [Mean Diff-Mean Difference; LOS-Level of Significance]

Table 3: Comparison of OLST score and falls efficacy scale score between pre-intervention and post intervention in Group A and Group B

\begin{tabular}{|c|c|c|c|c|c|c|}
\hline \multirow{2}{*}{\multicolumn{2}{|c|}{ Parameter }} & \multirow{2}{*}{ Sampling Stage } & Scatter & \multirow{2}{*}{ Mean Diff } & \multirow{2}{*}{ t-statistic } & \multirow{2}{*}{$\begin{array}{l}\text { p-value } \\
\text { (LOS) }\end{array}$} \\
\hline & & & Mean $\pm S D$ & & & \\
\hline \multirow{2}{*}{ 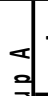 } & \multirow{2}{*}{ Time of OLST } & Pre-intervention & $4.84 \pm 1.65$ & \multirow{2}{*}{5.92 second } & \multirow{2}{*}{21.9} & \multirow{2}{*}{$p<0.001 \#$} \\
\hline & & Post Intervention & $10.76 \pm 1.33$ & & & \\
\hline \multirow{2}{*}{ 휜 } & \multirow{2}{*}{ FES-I (score) } & Pre- intervention & $39.44 \pm 5.11$ & \multirow{2}{*}{9.4 points } & \multirow{2}{*}{20.35} & \multirow{2}{*}{$p<0.001 \#$} \\
\hline & & Post Intervention & $30.04+5.50$ & & & \\
\hline \multirow{2}{*}{$\cong$} & \multirow{2}{*}{ Time of OLST } & Pre-intervention & $4.12 \pm 1.83$ & \multirow{2}{*}{8.44 second } & \multirow{2}{*}{23.38} & \multirow{2}{*}{$p<0.001 \#$} \\
\hline & & Post Intervention & $12.56 \pm 1.90$ & & & \\
\hline \multirow{2}{*}{ 니 } & \multirow{2}{*}{ FES-I (score) } & Pre-intervention & $38.88 \pm 6.02$ & \multirow{2}{*}{12.28 points } & \multirow{2}{*}{28.81} & \multirow{2}{*}{$p<0.001 \#$} \\
\hline & & Post Intervention & $26.60 \pm 4.89$ & & & \\
\hline
\end{tabular}

\# The mean differences are highly significant at the 0.001 level of significance. The degrees of freedom are 24. [Mean Diff-Mean Difference; LOS-Level of Significance]

Table 4: Comparison of scoring on berg balance scale between subjects of Group A and Group B at preintervention and post intervention stages.

\begin{tabular}{|c|c|c|c|c|c|}
\hline \multirow{2}{*}{ Sampling Stage } & \multirow{2}{*}{ Group } & Score on BBS & \multirow{2}{*}{ Mean Diff } & t-statistic & \multirow{2}{*}{ LOS } \\
\cline { 3 - 3 } & & Mean \pm SD & & & \\
\hline \multirow{2}{*}{ Pre-intervention } & Group A & $32.04 \pm 4.94$ & \multirow{2}{*}{0.16 points } & \multirow{2}{*}{0.1} & \multirow{2}{*}{ p $>0.05 @$} \\
\cline { 2 - 3 } & Group B & $31.88 \pm 5.95$ & & & \\
\hline \multirow{2}{*}{ Post-intervention } & Group A & $39.80 \pm 4.50$ & \multirow{2}{*}{3.44 points } & \multirow{2}{*}{2.44} & \multirow{2}{*}{ p<0.02* } \\
\cline { 2 - 3 } & Group B & $43.24 \pm 5.43$ & & & \\
\hline
\end{tabular}

$\otimes$ The mean difference is not significant (insignificant) at the 0.05 level of significance. ${ }^{*}$ The mean difference is significant at the 0.02 level of significance. [Mean Diff-Mean Difference; LOS-Level of Significance] 
Table 5: Measurement of change between groups at pre- intervention in OLST score and FES I Score.

\begin{tabular}{|c|c|c|c|c|c|}
\hline \multirow[t]{2}{*}{ Parameter } & \multirow{2}{*}{$\begin{array}{l}\text { Sampling Stage at } \\
\text { Pre- intervention }\end{array}$} & $\begin{array}{l}\text { Scatter at Pre- } \\
\text { intervention }\end{array}$ & \multirow[t]{2}{*}{ Mean Diff } & \multirow[t]{2}{*}{ t-statistic } & \multirow[t]{2}{*}{ LOS } \\
\hline & & Mean $\pm S D$ & & & \\
\hline \multirow{2}{*}{ Time of OLST } & Group A & $4.84 \pm 1.65$ & \multirow{2}{*}{0.72 second } & \multirow{2}{*}{1.46} & \multirow{2}{*}{$p>0.05 @$} \\
\hline & Group B & $4.12 \pm 1.83$ & & & \\
\hline \multirow{2}{*}{ FES-I (score) } & Group A & $39.44 \pm 5.11$ & \multirow{2}{*}{0.56 Points } & \multirow{2}{*}{0.36} & \multirow{2}{*}{$p>0.05 @$} \\
\hline & Group B & $38.88 \pm 6.02$ & & & \\
\hline
\end{tabular}

$\otimes$ The mean differences are not significant (insignificant) at the 0.05 level of significance. The degrees of freedom are 48. [Mean Diff-Mean Difference; LOS-Level of Significance]

Table 6: Measurement of change between groups at post intervention in OLST score and FES I Score.

\begin{tabular}{|c|c|c|c|c|c|}
\hline \multirow[t]{2}{*}{ Parameter } & \multirow[t]{2}{*}{ Group } & $\begin{array}{l}\text { Scatter at Post- } \\
\text { Intervention }\end{array}$ & \multirow[t]{2}{*}{ Mean Diff } & \multirow{2}{*}{ t-statistic } & \multirow[t]{2}{*}{ LOS } \\
\hline & & Mean $\pm S D$ & & & \\
\hline \multirow{2}{*}{ Time of OLST } & Group A & $10.76 \pm 1.33$ & \multirow{2}{*}{1.88 second } & \multirow{2}{*}{3.89} & \multirow{2}{*}{$p=0.000 \#$} \\
\hline & Group B & $12.56 \pm 1.90$ & & & \\
\hline \multirow{2}{*}{ FES-I (score) } & Group A & $30.04 \pm 5.50$ & \multirow{2}{*}{ 3.44 Points } & \multirow{2}{*}{2.34} & \multirow{2}{*}{$p=0.03$ * } \\
\hline & Group B & $26.60 \pm 4.89$ & & & \\
\hline
\end{tabular}

\# The mean differences are highly significant at the 0.001

level of significance. * The mean differences are significant at the 0.03 level of significance. The degrees of freedom are 48. [Mean Diff-Mean Difference; LOS-Level of Significance

Fifty $(\mathrm{N}=50)$ older adults of geriatric population were screened to evaluate the postural control, OLST Score and level of concern regarding falls during daily activities in order to record the effectiveness between general exercise program and specific exercise program. Selected older adults of geriatric population were allocated to a group randomly by using simple random sampling technique (lottery method) and distributed equally into two groups of equal size and for further statistical analysis designated as Group A ( $\left.n_{1}=25\right)$ and Group B $\left(n_{2}=25\right)$. The data collected prior to intervention in groups designated as Pre- intervention observation for sampling stage one. At second sampling stage, the data had re-recorded after four weeks of intervention of exercises was utilized as postintervention observations for further statistical analysis.

All these older adults of geriatric population subjects of Group A and Group B were planned to generate the effectiveness of general exercise program versus specific exercise program on balance for this comparative study purpose.

\section{DISCUSSION}

The findings of the study suggest that both the exercise Group benefitted from the interventions with a significant improvement in balance training. Individual Group Analysis indicated that those participants receiving the specific exercise program did better than the group receiving general exercise program. Improved scores in the Group B participants could be as a result of the composition of tasks they practiced in a specified manner. These tasks contained elements that encouraged participants to bend, turn and reach to limits of stability (e.g., while playing a game of ball catching and throwing) on various surfaces thereby providing added vestibular stimulation and target oriented approach. Vestibular stimulation occurs through various functional tasks such as reaching to limits of stability, sideways reaching tasks, and ball games. This vestibular stimulation is not focused on in the general exercise program. Though, it may not be the only cause of difference in performance of both groups, it does have a beneficial effect when we talk about balance exercise. Each workstation was designed to focus on a specific task that address different aspects required for balance including functional strength, flexibility, balance strategy practice, sensory integration, and added attention demands during function and multi-task practice. Such interventions encouraged speed and size of movements, which may have increased strength and endurance in addition to improving flexibility and reaction time for the specific exercise group.

Each station task was graded to cater to various levels of ability so that participants could have the level of difficulty progressed to increase the challenge. This versatility of degree of difficulty also allows for accommodation to various levels of ability of individual participants. This could have resulted in improved functional ability to balance, able to ambulate in the environment at a faster velocity. Support for this view comes from the improved outcomes from a similar multidimensional balance training program delivered as an individual intervention rather than small groups by Shumway et al. [3] Participants in specific balance- strategy program practiced ball games with varying size and 
weight. This might have increased manual reaction speed as noted by Botelloet al. [4] Improved hand eye coordination also helps in maintaining visual acuity during activities of daily living. Visual feed-back using the mirror provided to the subjectsduring various tasks on different surfaces thatmight have led to the enhancement in balance. This idea is supported by the findings of Sihvonen et al., [5] which suggest that balance training based on visual feedback improves balance control in frail elderly women living in residential care.

\section{CONCLUSION}

Current study concludes that the subjects who participated in the specific exercise program significantly improved their functional ability, OLST Score and decreased risk of falls as shown on the BBS, OLST-EO and FES-I compared to the general exercise program group.(p-0.001).Both the Groups A \& B are showing significant difference post intervention but on statistical analysis of mean difference Group B $(11.36 \pm 8.44 \pm 12.28)$ is statistically more significant compare to Group A(7.79 $\pm 5.92 \pm 9.40)$.

This was concluded statistically that the older adults of geriatric population intervened with specific exercise programhad more significantly improved postural control, OLST Score and level of concern regarding falls during daily activities than subjects intervened with general exercise program.

\section{Conflicts of interest: None}

\section{REFERENCES}

[1]. Gaurai Gharote, BiradarVijaykumar, Ujwayeole, Praveen Gawli, RoshanAdikitte, prevalence of balance alteration in geriatric population using berg balance scale 2016; 4(5):1679-83.

[2]. Shefaliwalia, majumi M.,Noohu. Comparison of two balance training program on balance in population dwelling older adults. 2016;2:32-35.

[3]. Shumway-Cook A, Gruber W, Baldwin M, Liao S. The effect of multidimensional exercises on balance, mobility, and fall risk in population dwelling older adults.PhysTher 1999;77:46-57.

[4]. Botelho MF, Azevedo A. Manual reaction speed and manual dexterity in elderly people: A comparative study between elderlypractitioners and nonpractioners of physical activity. Sport Sci 2009;2:3543.

[5]. Sihvonen SE, Sipila S, Era PA. Changes in postural balance in frail elderly women during a 4-week visual feedback training: a randomized controlled trial. Gerontology2004;50:87-95.

How to cite this article:

Divya Khare, Jyoti Shrivastava. COMPARISON OF TWO BALANCE TRAINING

PROGRAMS ON BALANCE OF GERIATRIC POPULATION OF MADHYA

PRADESH, INDIA. Int J Physiother Res 2018;6(2):2633-2636. DOI: 10.16965/ ijpr.2018.103 